\title{
Family Medicine and Obstetrics: Let's Stop Pretending
}

\author{
Richard A. Young, MD, and R. Levi Sundermeyer, MD
}

It is time to stop pretending that delivering babies is one of the core activities of family medicine.

At no time in the history of American family medicine have the majority of the members of the American Academy of Family Physicians (AAFP) delivered babies. A study in 1982 found that approximately $44 \%$ of family physicians delivered babies $^{1}$, another study reported $43 \%$ in $1986^{2}$, another $26 \%$ in $1993^{3}$, and the most recent data from the AAFP states the current number is $17.1 \%{ }^{4}$ The way forward from these trends should not be to continue business as usual.

Barreto et $\mathrm{al}^{5}$ found that $13 \%$ of 2016 family medicine residency graduates deliver babies. Almost half the respondents were not interested at all in obstetrics practice $(889 / 2018)$. Of those left who did not deliver babies, $60 \%$ mentioned lack of availability of jobs where family physicians in practice deliver babies as the reason and $60 \%$ mentioned lifestyle considerations, followed by malpractice costs and privileging challenges.

These realities have implications for family medicine residency education and the basket of services provided by its graduates.

\section{Reforming Education}

Recent experiments in family medicine residency education - the $\mathrm{P} 4$ project $^{6,7}$ and the Accreditation Council for Graduate Medical Education Length of Training Pilot (ACGME LoT) ${ }^{8}$ - have allowed for experimentation in the length and content of

From the JPS Family Medicine Residency Program, Fort Worth, TX.

Funding: none.

Conflict of interest: none declared.

Corresponding author: Richard A. Young, MD, JPS Family Medicine Residency Program, 1500 S. Main, Fort Worth, TX 76104 (E-mail: Ryoung01@jpshealth.org).

\section{See Related Article on Page 332.}

family medicine residencies. Our study of our early P4 graduates who completed a year of extra training in maternity care found they were much more likely to provide maternity care services, plus they were more likely to provide a wide basket of other services including caring for hospitalized adults and children, and performing hospital-based procedures. ${ }^{9}$ We have heard similar anecdotes from other programs offering extra training, and there is a literature on the effect of traditional obstetric fellowships on the provision of maternity care in practice, which found that roughly half of their graduates work in rural areas, at least for part of their early career, and roughly half become residency faculty. ${ }^{10,11}$

Our profession has had a considerable lively discussion of the role of maternity care in residency education, its requirements, and its impact on graduates' provision of these services. ${ }^{10-15}$ Residency characteristics associated with a higher likelihood of its graduates delivering babies included family medicine maternity care preceptors, $80+$ deliveries during residency, and greater autonomy in maternity care decision making. ${ }^{16}$ Cesarean sections may be a particularly important component of extended training options, as previous research reported an association between C-section training and its provision in rural practice. ${ }^{11,17} \mathrm{We}$ agree that all family physicians should know the basics of vaginal deliveries for at least 3 reasons: a positive experience in residency might convince the learner to consider maternity care on graduation; patients will ask questions about maternity care concerns even if the physician does not provide the service; and the physician might be called on to deliver a baby in an emergency. But for family medicine to continue to market itself as a comprehensive provider of maternity care services is misleading and undermines the public's perception of our specialty. ${ }^{18}$ Did our specialty ever really think that 40 vaginal deliveries was adequate to prepare a graduate to provide 
high-quality maternity care, especially if approximately one third of US deliveries are by cesarean section?

\section{Rural Health}

The American College of Obstetricians and Gynecologists $(\mathrm{OB} / \mathrm{GYN})$ recognized that most rural counties have no OB/GYNs, who vastly prefer to practice in urban settings. ${ }^{19}$ A survey of family medicine and OB/GYN residents confirmed that family medicine residents were more likely to provide maternity care services to rural areas $^{20}$ and other studies have found that family physicians provide a disproportionate share of rural deliveries. ${ }^{9,21}$

Greater travel distance to maternity care services is associated with worse perinatal outcomes. ${ }^{22}$ But rural hospitals are closing, especially labor and delivery units, a trend that has recently been reported in the lay press. ${ }^{23}$ It comes as no surprise that the decreasing percentage of family physicians providing prenatal and intrapartum care in rural areas has contributed to an increased number of rural communities with no local access to maternity care. ${ }^{24}$ Rural areas that lack local obstetric services are associated with less adequate prenatal care, higher rates of preterm delivery, infant mortality, and complications during delivery. ${ }^{25}$ In rural counties not adjacent to urban areas that lost obstetric services, increases were reported in out-of-hospital and preterm births and births in hospitals without obstetric units the following year. ${ }^{26}$

It is inconceivable that in our lifetimes family physicians will provide the majority of deliveries in urban America. Where might family physicians still deliver some urban babies? They can and should in family medicine residencies, a few remaining friendly oases in the Pacific Northwest, and a few independent inner city organizations serving vulnerable populations through Federally Qualified Health Centers or in some cases faith-based nongovernmental organizations.

But rural America is different. It makes no sense for OB/GYNs to deliver the majority of those babies both for reasons of professional life and the business model. There are simply not enough cases in many rural communities to feed the OB/GYNs enough business to thrive with capable OB/GYN partners in those communities. Family physicians can be kept busy when they are not providing maternity care by addressing all the other patient concerns not limited by symptom, disease, gender, or age; OB/GYNs cannot. A recent survey of rural hospital executives found the more isolated and smaller volume hospitals are much more reliant on family physicians to deliver babies, but they are still present in the larger rural hospitals. ${ }^{9}$ We know that maternal or child outcomes are similar between family physicians and OB/GYNs performing cesarean sections ${ }^{27,28}$, so that issue is moot.

\section{The Way Forward}

Everyone who cares about the wellbeing of mothers and their babies from vulnerable populations (in this case, mostly rural, but some urban) should advocate for 2 things. First, after recognizing that only a subset of family physicians are adequately trained and capable of providing comprehensive maternity care services in these isolated and/or underserved environments, to advocate that their residency education be better supported so that more of them can provide these services in practice, which will often require extra training time. The OB/GYN world has even commented on the negative impact of the duty hour rules on preparing physicians in their residencies for practice after graduation. ${ }^{29}$

Think of extra maternity care training as like a merit badge in scouting. All family physicians possess key characteristics - a broad base of knowledge and skills to manage over 1600 symptoms and diagnoses ${ }^{30}$ possessed by physicians who make medical care decisions guided by a deep knowledge of the whole patient combined with a comfort with uncertainty $^{31}$ - but only a few have had the extra training to competently, confidently, and independently graduate from the training environment to deliver maternity care services. The ACGME LoT experiment may shed further light on the educational specifics required to achieve this outcome. ${ }^{8}$ Extra training opportunities in 4-year residencies should be funded consistent with standard graduate medical education funding as 1 option (or better yet, better) and traditional obstetrics fellowships should also be an option.

The second advocacy need is for family medicine graduates to have sustainable rural health care systems to work in, both in payment for physician services and to rural hospitals. All physicians thrive when they have competent and trusted colleagues 
to work with, which makes the 3:00 am deliveries that much more tolerable. This may be especially important for rural women family physicians. ${ }^{32}$ Unfortunately, the realities of health care financing often do not support this physician or hospital infrastructure. Closed rural obstetric units were smaller units in lower-income communities ${ }^{24,33}$, but an additional family physician per 10,000 in the community was associated with a $38 \%$ decrease in the odds of unit closure. ${ }^{24}$ The lack of family physicians delivering babies is especially a problem of the Eastern United States. ${ }^{9}$ The markedly higher medical malpractice costs in many Eastern states without tort reform probably has a large role in this finding. ${ }^{34}$ Decreasing malpractice costs is a key component of both expanding maternity care training opportunities in residencies and encouraging young family physicians to deliver babies in practice. ${ }^{35}$ Funding of Medicaid and nonfee-for-service payment mechanisms (rural health clinics, e.g.) should also be improved.

Addressing recent graduates' concerns that they do not see family physicians delivering babies in the "real world" can only be addressed with an enhanced residency experience in maternity care and a viable practice to work in after they graduate. Just as in other issues of health care disparities, being born in rural or urban underserved America should not be a reason for babies and their mothers to have worse outcomes. ${ }^{36}$ More well-trained and supported family physicians delivering babies, and the rural hospitals they work in, are the best solution to this problem.

To see this article online, please go to: http://jabfm.org/content/ 31/3/328.full.

\section{References}

1. Rosenblatt RA, Cherkin DC, Schneeweiss R, et al. The structure and content of family practice: Current status and future trends. J Fam Pract 1982;15: 681-722.

2. Cohen D, Coco A. Declining trends in the provision of prenatal care visits by family physicians. Ann Fam Med 2009;7:128-33.

3. Kahn NB Jr, Schmittling G. Obstetric privileges for family physicians: A national study. J Am Board Fam Pract 1995;8:120-7.

4. American Academy of Family Physicians. Family medicine facts, Table 11: Clinical services performed by physicians. Available from: https://www.aafp.org/ about/the-aafp/family-medicine-facts/table-11(rev). html. Accessed Feb 19, 2018.
5. Barreto TW, Eden AR, Rose Hansen E, Peterson LE. Barriers faced by family medicine graduates interested in including obstetric deliveries in their practice. J Am Board Fam Med 2018;31:332-333.

6. Green LA, Jones SM, Fetter G Jr, Pugno PA. Preparing the personal physician for practice: Changing family medicine residency training to enable new model practice. Acad Med 2007;82:1220-27.

7. LoPresti L, Young R, Douglass A. Learner-directed intentional diversification: The experience of three P4 programs. Fam Med Feb 2011;43:114-6.

8. ACGME pilot project to test four-year family medicine residency AAFP. Available from: http://www. aafp.org/news/education-professional-development/ 20120427acgmepilot.html. Accessed Jan 27, 2016.

9. Young RA. Maternity care services provided by family physicians in rural hospitals. J Am Board Fam Med 2017;30:71-7.

10. Chang Pecci C, Leeman L, Wilkinson J. Family medicine obstetrics fellowship graduates: Training and post-fellowship experience. Fam Med 2008;40: 326-32.

11. Rodney WM, Martinez C, Collins M, Laurence G, Pean C, Stallings J. OB fellowship outcomes 19922010: Where do they go, who stops delivering, and why? Fam Med 2010;42:712-6.

12. Coonrod RA, Kelly BF, Ellert W, Loeliger SF, Rodney WM, Deutchman M. Tiered maternity care training in family medicine. Fam Med 2011;43:631-7.

13. Meunier MR, Apgar BS, Ratcliffe SD, Mullan PB. Plans to accommodate proposed maternity care training requirements: A national survey of family medicine directors of obstetrics curricula. J Am Board Fam Med 2012;25:827-31.

14. Deutchman M, Connor P, Gobbo R, FitzSimmons R. Outcomes of cesarean sections performed by family physicians and the training they received: A 15year retrospective study. J Am Board Fam Pract 1995;8:81-90.

15. Orientale E Jr. Length of training debate in family medicine: Idealism versus realism? J Grad Med Educ 2013;5:192-4.

16. Sutter MB, Prasad R, Roberts MB, Magee SR. Teaching maternity care in family medicine residencies: What factors predict graduate continuation of obstetrics? A 2013 CERA program directors study. Fam Med Jun 2015;47:459-65.

17. Norris TE, Reese JW, Pirani MJ, Rosenblatt RA. Are rural family physicians comfortable performing cesarean sections? J Fam Pract 1996;43:455-60.

18. Martin JC, Avant RF, Bowman MA, et al. The future of family medicine: A collaborative project of the family medicine community. Ann Fam Med 2004;1: S3-S32.

19. Rayburn WF, Klagholz JC, Murray-Krezan C, Dowell LE, Strunk AL. Distribution of American Congress of Obstetricians and Gynecologists fellows 
and junior fellows in practice in the United States. Obstet Gynecol 2012;119:1017-22.

20. Gladu R, Lange G, Groff J. Current status \& future supply of providers. Texas Fam Physician 1998:14-6.

21. Cohen D, Guirguis-Blake J, Jack B, et al. Family physicians make a substantial contribution to maternity care: The case of the state of Maine. Am Fam Physician 2003;68:405.

22. Grzybowski S, Stoll K, Kornelsen J. Distance matters: A population based study examining access to maternity services for rural women. BMC Health Serv Res 2011;11:147.

23. Kozhimannil KB, Frakt A. Rural America's disappearing maternity care. Washington Post. Nov 8, 2017.

24. Hung P, Kozhimannil KB, Casey MM, Moscovice IS. Why are obstetric units in rural hospitals closing their doors? Health Serv Res 2016;51:1546-60.

25. Nesbitt TS, Larson EH, Rosenblatt RA, Hart LG. Access to maternity care in rural Washington: Its effect on neonatal outcomes and resource use. Am J Public Health 1997;87:85-90.

26. Kozhimannil KB, Hung P, Henning-Smith C, Casey MM, Prasad S. Association between loss of hospitalbased obstetric services and birth outcomes in rural counties in the United States. JAMA 2018;319: $1239-47$.

27. Homan FF, Olson AL, Johnson DJ. A comparison of cesarean delivery outcomes for rural family physicians and obstetricians. J Am Board Fam Med 2013; 26:366-72.

28. Aubrey-Bassler K, Cullen RM, Simms A, et al. Outcomes of deliveries by family physicians or obstetri- cians: A population-based cohort study using an instrumental variable. CMAJ 2015;187:1125-32.

29. Blanchard MH. Work ... life ... balance? Obstet Gynecol 2012;119:177-9.

30. Peabody MR, O’Neill TR, Stelter KL, Puffer JC. Frequency and criticality of diagnoses in family medicine practices: From the National Ambulatory Med Care Survey (NAMCS). J Am Board Fam Med 2018; 31:126-38.

31. Young R, Burge S, Benold T, Hill J, Bayles B. Family medicine's association with cost-effective care: A qualitative explanatory study from the Research Residency Network of Texas. 2011.

32. Phillips J, Hustedde C, Bjorkman S, et al. Rural women family physicians: Strategies for successful work-life balance. Ann Fam Med 2016;14:244-51.

33. Kaufman BG, Thomas SR, Randolph RK, et al. The rising rate of rural hospital closures. J Rural Health 2016;32:35-43.

34. Robinson P, Xu X, Keeton K, Fenner D, Johnson TR, Ransom S. The impact of medical legal risk on obstetrician-gynecologist supply. Obstet Gynecol 2005;105:1296-1302.

35. Nesbitt TS, Kahn NB, Tanji JL, Scherger JE. Factors influencing family physicians to continue providing obstetric care. West J Med 1992;157:44-47.

36. Ely D, Hoyert D. Differences between rural and urban areas in mortality rates for the leading causes of infant death: United States, 2013-2015. NCHS data brief, no. 300, February 2018. Available from: https://www.cdc.gov/nchs/data/databriefs/db300. pdf. Accessed Feb 22, 2018. 